\title{
COLOR DOPPLER ULTRASOUND IN EVALUATION OF SCROTAL LESIONS
}

\author{
Desai Sanjay $D^{1}$
}

${ }^{1}$ Associate Professor, Department of Radiology, RCSM Govt. Medical College, Kolhapur.

ABSTRACT: Color Doppler ultrasound is a non-invasive, non-ionising and rapid method for scrotal examination. The present study is carried out to evaluate clinically suspected cases of scrotal lesions, the sensitivity, specificity of color doppler.

MATERIAL AND METHODS: This prospective study comprises 120 patients of different age groups with clinical suspicion of scrotal lesions. Color doppler ultrasound was done with $7.5 \mathrm{MHz}$ transducer.

RESULTS: Of the total 120 cases, benign conditions 111 (92.5\%) is more common than malignant 9 (7.5\%). In benign group commonest diagnoses were hydrocele, epididymo-orchitis, varicocele and epididymal cyst. In malignant group teratocarcinoma, choriocarcinoma, seminoma, lymphoma, embryonal cell carcinoma, yolk sac tumor with teratocarcinoma. The sensitivity for diagnosing extratesticular lesions was $83.14 \%$ and for testicular lesions $88.57 \%$.

CONCLUSION: Color doppler ultrasound is helpful in differentiating extratesticular and intratesticular lesions. It should be performed in all patients with suspected scrotal lesions.

KEYWORDS: Epididymo-Orchitis, Orchitis, Scrotal Lesions, Hydrocele.

HOW TO CITE THIS ARTICLE: Desai Sanjay D. "Color Doppler Ultrasound in Evaluation of Scrotal Lesions." Journal of Evolution of Medical and Dental Sciences 2015; Vol. 4, Issue 94, November 23; Page: 16002-16006, DOI: 10.14260/jemds/2015/2333.

INTRODUCTION: Color Doppler ultrasound is a noninvasive, non-ionising and rapid method for scrotal examination. Capabilities have made it possible to identify and analyse extremely small vessels. This ability has had a dramatic impact in evaluation of the scrotum and has allowed Doppler sonography to assume an important role as a definitive diagnostic test as well as a screening modality. Scrotal disorders may be congenital, inflammatory, neoplastic, traumatic, vascular or idiopathic in origin. Proper clinical history and examination is must prior to ultrasound examination of scrotum. Scrotal ultrasound when interpreted with the appropriate clinical background can provide definite diagnosis and materially help in patient management.

Usually the patient referred for scrotal ultrasound are complaining of acute scrotum, scrotal swelling, scrotal trauma, impalpable testes and male infertility. Color Doppler is the most useful and most rapid technique to establish the diagnosis of testicular torsion and to help distinguish torsion from epididymo-orchitis. ${ }^{1}$ In cases of scrotal swelling, ultrasound plays a vital role in localisation (Testicular or extra testicular) and characterization (Cystic or solid) of the lesion. Clinical examination may be unsatisfactory due to scrotal swelling. Color Doppler Ultrasound helps to determine integrity of testis following trauma, detects undescended testicles in cord which may be impalpable by clinical examination.

Financial or Other, Competing Interest: None.

Submission 04-11-2015, Peer Review 05-11-2015,

Acceptance 13-11-2015, Published 23-11-2015.

Corresponding Author:

Dr. Desai Sanjay D,

"Vivek;" Polt No-165,

Rajopadhye Nagar,

Kolhapur-416012,

Maharashtra.

E-mail: drsanjaydesai@rediffmail.com

DOI:10.14260/jemds/2015/2333.
The present study is carried out to evaluate the clinically suspected cases of scrotal lesions, the sensitivity and specificity of color Doppler ultrasound and to differentiate between benign and malignant masses.

MATERIAL AND METHODS: This is a prospective study carried out in the Department of Radiodiagnosis, RCSM Govt Medical College, Kolhapur. This study comprises 120 patients of different age groups in whom there was clinical suspicion of scrotal lesions. The color Doppler ultrasound was done with $7.5 \mathrm{Mhz}$ transducer. This transducer operates for both real time grey and Doppler imaging. Both testes scanned for their size, shape, echogenicity and echopattem. The relationship of the epididymis to the testis was noted.

Epididymis was studied in relation to its head, body and tail and also size and echotexture. The site of pathology and its echotexture were evaluated with emphasis on differentiation of intra- and extra-testicular lesions. Solid or cystic nature of the lesion was detected. In evaluation of varicoceles, the examination was done in the standing position and the patient was asked to perform Valsalva's maneuver. Color Doppler study was done in cases with suspected inflammatory conditions cases with suspected torsion to differentiate from inflammatory conditions, to detect sub-clinical varicoceles and to study the intra-testicular as well as extra-testicular lesions.

RESULTS: The results are presented in the form of tables [Tables 1-9]. The results were compared with the pathological and post-operative findings. The 120 cases which were evaluated, benign conditions 111 (92.5\%) were found to be more common than malignant 9 (7.5\%). Incidence of benign conditions was at higher side than malignant. Majority of the patients presenting with scrotal lesions were found to be of age group between 21-30 years (26 cases) and second and third age group were 11-20 years (23 cases) and 0-10 year (21 cases) respectively. 
The most common age group for testicular malignancy was 21-30 years (3 cases). The youngest patient in the present study was 24 days of age and older patient was 80 years of age. In the benign group the commonest diagnosis were hydrocele 40 (33.33\%), epididymo-orchitis 13 (10.8\%), varicocele $13(10.8 \%)$ and epididymal cyst 13 (10.8\%). Hydrocele most often appears in middle aged or elderly men, but is not uncommon in early childhood.2 In the present study, 33 out of 111 benign lesions were in the age group 2130 years. The maximum number of benign and malignant masses were in the age group of 11-40 years and 51-70 years.

In the present study, all malignant lesions were in the group of 2-68 years. Of the total malignant lesions, two each of teratocarcinoma (22.22\%), choriocarcinoma $(22.22 \%)$ and seminoma (22.22\%), one each of lymphoma (11.11\%) embryonal cell carcinoma (11.11\%), Yolk sac tumour with teratoma $(11.11 \%)$. Bailey and Love. ${ }^{2}$ reported seminoma was $40 \%$ and teratoma was $32 \%$. William G. Horstman. ${ }^{3}$ reported that seminoma $30 \%$, embryonal cell carcinoma $25 \%$, and teratoma $25 \%$. In our study percentage of seminoma was $22.2 \%$ compared with Williams Horstman., 3 where it is $30 \%$. In the present study, age group for seminoma was 42 years, consistent with Bailey and Love. ${ }^{2}$ (40-50).

One case of embryonal cell carcinoma was having age of 32 years consistent with Robert Lee Bree. ${ }^{4}$ The total percentage of testicular malignancy in present study was $7.5 \%$. Testicular tumours represent only $1 \%$ to $2 \%$ of malignant tumours, but are the most common malignancies in young men. ${ }^{2,3}$ of the total 35 cases diagnosis of hydrocele proved surgically, 9 were congenital hydroceles (Inguinoscrotal), 5 were encysted hydrocele of cord, both congenital hydrocele and encysted hydrocele of cord confirmed by postoperative findings. Of the total 120 cases, 26 cases were treated conservatively on the basis of color Doppler US diagnosis and 94 cases had undergone surgery.

In our study, the most common benign lesion were hydrocele, which appears as anechoic collection in layers of tunica vaginalis surrounding the antero-lateral portion of testis. In chronic cases we got internal echoes, septation and caused difficulty in differentiating the condition from pyocele or haematocele. In chronic hydrocele, internal echoes were due to presence of cholesterol and tyrosine crystals, which were proved cytologically. In the setting of acute and chronic infection, it may be impossible to determine whether such abnormalities represent an uncomplicated hydrocele or infected one with pyogenic debris or haemorrhage.

Septations may occur in uncomplicated hydrocele, but are usually associated with infection or haemorrhages. ${ }^{5}$ Next most common group of benign lesions occurred in our study were varicocele. There were $13(10.8 \%)$ cases of varicocele; $10(70 \%)$ were on left side and 3 (23\%) were on right side; predominance of varicocele on the left side owing to venous drainage through the left renal vein. The left renal vein is subject to compression by the abdominal aorta and superior mesenteric artery, additionally left internal spermatic vein drains into the left renal vein at right angle. ${ }^{4}$ In all 13 cases, abdominal scanning was done to rule out any retroperitoneal mass.
Williams A. Horstmann. ${ }^{3}$ stated that primary unilateral varicocele are rare; when one is encountered, the possibility of retroperitoneal mass obstructing the right spermatic vein should be investigated. ${ }^{3}$ Out of 7 clinically diagnosed varicocele cases, only 4 cases were diagnosed on color Doppler ultrasound, 3 cases were false positively clinically diagnosed. Out of 13 varicocles, 6 varicoceles are diagnosed as associated findings in various clinical diagnosis like hydrocele, torsion of testis, orchitis, epididymo-orchitis and testicular atrophy and infertility. Color Doppler ultrasound detected 13 of 13 (100\%) varicoceles. Color Doppler ultrasound is capable of detecting subclinical varicoceles and also directs more reliably further diagnostic testing than physical examination alone. ${ }^{6}$

The next commonest benign lesion was acute epididymo-orchitis 13 cases (10.8\%). Clinically, 15 cases were presented as epididymo-orchitis, but with color Doppler US only 6 cases (5\%) were diagnosed as epididymo-orchitis; with color Doppler US appearances as enlarged epididymis and testicle with decreased echotexture or heterogenous echotexture with increased vascularity. Of the 13 diagnosed cases of epididymo-orchitis, 7 cases were diagnosed as epididymo-orchitis as an alternative findings where clinical diagnosis were false negative.

Out of $4(3.33 \%)$ pathologically proved cases of orchitis, only $3(2.5 \%)$ cases were diagnosed as orchitis and one case $(0.83 \%)$ was false positively diagnosed as developing, seminoma which on follow-up scans and antibiotic trial proved focal orchitis pathologically. Out of 4 diagnosed cases of epididymitis on color Doppler ultrasound, 3 were having epididymitis, one case which was false positively diagnosed proved surgically as torsion of testis with relative hyperaemia of epididymis. Out of 4 cases of epididymitis, 3 cases shows venous flow. William C. Horstman. ${ }^{7}$ detected venous flow in epididymitis and orchitis.

This occurred in 3 of 45 cases of epididymal inflammation and 5 of 21 cases of testicular inflammation. Venous flow is almost never seen normally; therefore, its detection should raise suspicion of underlying inflammation. Of the total 120 cases 5 were epididymal cysts, appear on color Doppler US as anechoic lesions without internal echoes with good posterior transmission of sound; sometimes septations were seen commonly in head of epididymis. Clinically 13 cases were presented as epididymal cysts, of which 5 were correctly diagnosed on color Doppler ultrasound and proved post-operatively.

Two cases were diagnosed as hydrocele and hematocele postoperatively, which were false positively diagnosed as epididymal cysts. Next most common group of benign lesions occurs in our study was inguino-scrotal hernia or swelling. There were $3(2.5 \%)$ cases, which were diagnosed sonologically and proved postoperatively. Out of $12(10 \%)$ clinically diagnosed cases of inguino-scrotal hernia, $2(1.5 \%)$ were having inguino-scrotal hernia on color Doppler US. On ultrasonography hernia appears as complex mass separate from testicle and bowels were easily identified by the presence of haustrations of large bowel and valvulae conniventes of small bowel within the scrotum. 
Bailey and Love. ${ }^{2}$ stated about 5\% inguinal hernias were associated with vaginal hydroceles of the same side.

Thus identification of both hernia and hydrocele gives valuable information to surgeons as to the extent of incision. In present study, 3 cases presented clinically with torsion. Of the total 3 cases, 2 cases were proved surgically as torsion. Out of these 2 cases, one case is false positively diagnosed as epididymitis. Heidi B. Patriquin., ${ }^{8}$ stated that surgery revealed 19 cases of testicular torsion, 17 were diagnosed with Doppler sonography.

Doppler sonography yielded a sensitivity of $89 \%$ and specificity of $100 \%$. Doland D Burks. ${ }^{9}$ stated using the single criterion of presence and absence of identifiable intratesticular flow, color Doppler was $86 \%$ sensitive, $100 \%$ specific and $97 \%$ accurate in diagnosis of torsion and ischemia in the painful scrotum. Color Doppler sonography is accurate, non-invasive means of rapidly assessing perfusion of the testis in the painful scrotum. In present study there were 2 cases of atrophic testis, which were of very small size compared with normal testis and eco-texture was slightly increased.

In two patients we diagnosed herniated mesenteric fat as a mass of heterogeneous echotexture predominating echogenic, but in one case it was lipoma of spermatic cord confirmed histopathologically. In two cases there were multiple echoreflective structures scattered throughout testicular parenchyma suggestive of testicular microlithiasis, but there was an evidence of malignant lesion on scanning in one case, so we advised followup. Mark L. Backus. ${ }^{10}$ stated testicular microlithiasis has a characteristic sonographic appearance. Because of the $40 \%$ occurrence of primary testicular neoplasm in association with it, testicular microlithiasis cannot continue to be considered as a benign finding.

There was one case of epidermoid cyst, which is well defined avascular mass with characteristic whorled appearance, like the layers of an onion skin. Malvica R. P.11 stated another typical appearance of epidermoid cyst is a well-defined hypoechoic mass with an echogenic capsule. It may also have the nonspecific appearance of a hypoechoic mass with or without calcification. Avascularity is a clue to the diagnosis. There were two cases of testicular abscess showing enlarged testes with mass containing moving echoes within it and mixed echogenic areas. There were two cases of scrotal wall abscess which proved pathologically and one is false positively clinically diagnosed as pyocele and another one was diagnosed clinically as testicular malignancy.

In present study, we classified the scrotal swellings as extra-testicular and testicular. Of total 120 cases, 83 $(69.16 \%)$ were extra-testicular and 37 (30.83\%) were testicular swellings. The sensitivity for diagnosing extratesticular lesions was $83.14 \%$ and for testicular lesions was $88.57 \%$. Ultrasound had accuracy rate of 90 to $95 \%$ in differentiation of testicular and extra-testicular lesion. ${ }^{4}$ Ultrasound can differentiate intra and extra-testicular masses with an accuracy $98 \%$ and $100 \% .{ }^{5}$ In our study the sensitivity for detection of testicular malignancy was $90 \%$, specificity $100 \%$, overall accuracy was $100 \%$, positive predictive value $100 \%$ and negative predictive value $99.09 \%$.
CONCLUSION: Benign lesions were found to be more common than malignant. Maximum number of patients were in 21-30 years of age group. The most common age group for testicular malignancy was 21-30 years. In the benign lesions, the most common diagnosis were hydrocele followed by epididymo-orchitis, varicocele, epididymal cyst. The sensitivity for detection of testicular malignancy was $90 \%$. The specificity for detection of testicular malignancy was $100 \%$. The overall accuracy for detection of testicular tumor was $100 \%$. The overall diagnostic accuracy of color Doppler US in detection of scrotal disorder was $90 \%$.

Color Doppler US was helpful in differentiating extratesticular and intratesticular lesions. Hydrocele and more complex fluid collections are easily identified such as epididymal cyst, hematocele, pyocele. In patients presenting with a hydrocele of uncertain aetiology and in which the underlying structures cannot be freely palpated, color Doppler US provides a useful and accurate means of excluding underlying pathology such as inflammatory. Color Doppler US has also been shown to be useful in the diagnosis of malignant tumor in palpably normal testis and facilitate an early diagnosis in patients with testicular cancer.

Varicocele were found more frequently on left side than right side. There is no accurate way of using color Doppler US criteria to distinguish between benign and malignant testicular lesions. Color Doppler US provides valuable information which helps to improve the management of patients with scrotal lesions. Color Doppler ultrasound provides simultaneous display of tissue morphology in grey scale and blood flow in color.

It has potential to combine the advantages of both conventional ultrasound and testicular scintigraphy in the evaluation of scrotal lesions. Color Doppler ultrasound is effective in the clinical evaluation of acute scrotal disorders. Because epididymitis, epididymo-orchitis and orchitis are the most commonly encountered causes of acute scrotal pain. Thus color Doppler ultrasonography should be performed in all patients with suspected testicular lesions based on history and clinical findings.

\section{REFERENCES}

1. Carol M. Rumack Diagnostic ultrasound 4th edition volume 2 , 21: 846-869.

2. Bailey and Loves's: Short practice of surgery, 24th Ed. 2004: 1403-1416.

3. William G. Horstman: Scrotal imaging. Urologic Clinics of North America, Vol. 24, No.3,1997: 653-671.

4. Robert L. Bree: Scrotal ultrasound: Radiologic Clinics of North America, Vol. 34. No. 6, 1996: 1183-1205.

5. Kenneth D. Krone: Scrotal ultrasound. Radiologic Clinics of North America. Vol. 23, No. I., 121-139.

6. John A. Petros: Correlation of testicular color Doppler Ultrasonogrpahy, Physical examination and venography in the detection of left varicoceles in men with infertility. J. Urol. 1991: 145: 785-788.

7. William G. Horstman: Scrotal inflammatory disease: Color Doppler US findings. Radiology, 1991: 1 79: 55-59.

8. Heidi B. Patriquin: Testicular torsion in infants and children: Diagnosis with Doppler sonography. Radiology1993:188:781- 785. 
9. Burks D. D: Suspected testicular torsion and ischemia. Evaluation with color Doppler sonography. Radiology1990:175: 815-821.

10. Mark L. Backus: Testicular microlithiasis: Imaging appearances and pathological correction. Radiology1994:192: 785-785.

11. Malvica R. P: Epidermoid cyst of the testicle. An unusual sonographic findings. AJR, 1992 160: 1047-1048.

\begin{tabular}{|c|c|c|}
\hline $\begin{array}{c}\text { Age Group in } \\
\text { Years }\end{array}$ & No. of Cases & Percentage \\
\hline $0-10$ & 21 & 17.5 \\
\hline $11-20$ & 23 & 19.7 \\
\hline $21-30$ & 26 & 21.7 \\
\hline $31-40$ & 20 & 6.7 \\
\hline $41-50$ & 9 & 7.5 \\
\hline $51-60$ & 6 & 5 \\
\hline $61-70$ & 13 & 0.8 \\
\hline $71-80$ & 2 & 1.67 \\
\hline Total & $\mathbf{1 2 0}$ & $\mathbf{1 0 0}$ \\
\hline \multicolumn{3}{|c|}{ Table 1: Age Distribution } \\
\hline
\end{tabular}

\begin{tabular}{|c|c|c|}
\hline Side & No. of Cases & Percentage \\
\hline Unilateral & 102 & 85 \\
\hline Bilateral & 18 & 15 \\
\hline Total & $\mathbf{1 2 0}$ & $\mathbf{1 0 0}$ \\
\hline \multicolumn{3}{|c|}{ Table 2: Distribution of cases having } \\
unilateral and bilateral scrotal lesions
\end{tabular}

\begin{tabular}{|c|c|c|c|c|c|c|}
\hline \multirow{2}{*}{$\begin{array}{c}\text { Age } \\
\text { Group in } \\
\text { Years }\end{array}$} & \multicolumn{2}{|c|}{ Benign } & \multicolumn{2}{|c|}{ Malignant } & \multicolumn{2}{|c|}{ Total } \\
\hline & No. & $\%$ & No. & $\%$ & No. & $\%$ \\
\hline $0-10$ & 20 & 16.7 & 1 & 0.83 & 21 & 17.5 \\
\hline $11-20$ & 21 & 17.5 & 2 & 1.66 & 23 & 19.2 \\
\hline $21-30$ & 33 & 27.5 & 3 & 2.50 & 26 & 21.7 \\
\hline $31-40$ & 19 & 15.8 & 1 & 0.83 & 20 & 16.7 \\
\hline $41-50$ & 8 & 6.67 & 1 & 0.83 & 9 & 7.5 \\
\hline $51-60$ & 6 & 5 & 0 & 0 & 6 & 5.0 \\
\hline $61-70$ & 12 & 10 & 1 & 0.83 & 13 & 10.8 \\
\hline $71-80$ & 2 & 1.66 & 0 & 0 & 2 & 1.67 \\
\hline Total & 111 & 92.5 & 9 & 7.5 & 120 & 100 \\
\hline
\end{tabular}

\begin{tabular}{|c|c|c|c|c|c|c|}
\hline \multirow{3}{*}{ Scrotal Lesions } & \multirow{2}{*}{\multicolumn{2}{|c|}{ Clinical Diagnosis }} & \multicolumn{4}{|c|}{ Color Doppler US Diagnosis } \\
\hline & & & & Positive & & Negative \\
\hline & No & $\%$ & No & $\%$ & No & $\%$ \\
\hline Hydrocele & 39 & 29.2 & 19 & 15.8 & 16 & 13.33 \\
\hline Varicocele & 17 & 5.83 & 4 & 3.33 & 3 & 2.5 \\
\hline Testicular malignancy & 16 & 13.33 & 8 & 6.67 & 8 & 6.67 \\
\hline Inguinoscrotal hernia & 12 & 10 & 2 & 1.67 & 10 & 8.33 \\
\hline Epidymoorchitis & 29 & 12.5 & 6 & 5 & 9 & 7.5 \\
\hline Torsion of testes & 7 & 2.5 & 1 & 0.83 & 2 & 1.67 \\
\hline Total & 120 & 100 & 54 & 45 & 66 & 55 \\
\hline & $\begin{array}{l}\text { le 4: ? } \\
\text { with }\end{array}$ & $\begin{array}{l}\text { stribut } \\
\text { al and }\end{array}$ & ases & $\begin{array}{l}\text { scrotal } \\
\text { diagno }\end{array}$ & & \\
\hline
\end{tabular}

\begin{tabular}{|c|c|c|c|c|}
\hline \multirow{2}{*}{ Scrotal Lesion } & \multicolumn{2}{|c|}{ Color Doppler US Diagnosis } & \multicolumn{2}{|c|}{ Final Diagnosis } \\
\hline & No & $\%$ & No & $\%$ \\
\hline Hydrocele & 42 & 33.33 & 35 & 29.2 \\
\hline Epididymoorchitis & 20 & 10.8 & 13 & 10.8 \\
\hline Testicular abscess & 2 & 1.67 & 2 & 1.67 \\
\hline Varicocele & 13 & 10.8 & 13 & 10.8 \\
\hline Epididymal cyst & 13 & 10.8 & 5 & 4.17 \\
\hline Testicular malignancy & 9 & 7.5 & 9 & 7.5 \\
\hline Atrophic testes & 2 & 1.67 & 2 & 1.67 \\
\hline Undescended testis & 8 & 6.67 & 6 & 5 \\
\hline Torsion of testis & 1 & 0.83 & 2 & 1.67 \\
\hline Inguinoscrotal hernia & 3 & 2.5 & 3 & 2.5 \\
\hline Testicular microlithiasis & 2 & 1.67 & 2 & 1.67 \\
\hline Epidermoid cyst & 1 & 0.83 & 1 & 0.83 \\
\hline Herniated mesenteric fat & 2 & 1.67 & 1 & 0.83 \\
\hline Scrotal wall abscess & 2 & 1.67 & 2 & 1.67 \\
\hline Lipoma of cord & 0 & 0 & 1 & 0.83 \\
\hline Total & 120 & 100 & 109 & 90.8 \\
\hline \multicolumn{5}{|c|}{$\begin{array}{c}\text { Table 5: Distribution of scrotal color } \\
\text { Doppler US and Final diagnosis }\end{array}$} \\
\hline
\end{tabular}




\begin{tabular}{|c|c|c|c|c|}
\hline $\begin{array}{c}\text { Scrotal } \\
\text { Lesion }\end{array}$ & \multicolumn{2}{|c|}{$\begin{array}{c}\text { Color Doppler US } \\
\text { Diagnosis }\end{array}$} & \multicolumn{2}{c|}{ Final Diagnosis } \\
\hline & No. & $\%$ & No. & $\%$ \\
\hline Benign & 111 & 92.5 & 100 & 83.33 \\
\hline Malignant & 9 & 7.5 & 9 & 7.5 \\
\hline Total & 120 & 100 & 109 & $\mathbf{9 0 . 8 3}$ \\
\hline \multicolumn{4}{|c|}{$\begin{array}{r}\text { Table 6: Distribution of benign } \\
\text { and malignant cases }\end{array}$} \\
\hline
\end{tabular}

\begin{tabular}{|c|c|c|}
\hline Side & Varicocele & $\mathbf{\%}$ \\
\hline Right & 3 & 23 \\
\hline Left & 10 & 77 \\
\hline Total & 13 & 100 \\
\hline \multicolumn{2}{|c|}{ Table 7: Distribution of varicoceles } \\
on right and left \\
\hline
\end{tabular}

\begin{tabular}{|l|c|c|}
\hline \multicolumn{1}{|c|}{ Scrotal Lesions } & No. & \% \\
\hline Extra Testicular & $\mathbf{0}$ & $\mathbf{0}$ \\
\hline Testicular & 2 & 22.22 \\
1. Teratocarcinoma & 2 & 22.22 \\
2. Choriocarcinoma & 1 & 11.11 \\
3. Lymphoma & 2 & 22.22 \\
4. Seminoma & 1 & 11.11 \\
5. Yolk sac tumor + teratoma & 1 & 11.11 \\
6. Embryonal cell carcinoma & $\mathbf{9}$ & $\mathbf{1 0 0}$ \\
\hline \multicolumn{2}{|c|}{ Total } & \\
\hline \multicolumn{2}{|c|}{ Table 9: Distribution of malignant } \\
\hline
\end{tabular}

\begin{tabular}{|c|c|c|c|c|}
\hline $\begin{array}{c}\text { Scrotal } \\
\text { Lesion }\end{array}$ & $\begin{array}{c}\text { Color } \\
\text { Doppler } \\
\text { US } \\
\text { Diagnosis }\end{array}$ & & $\begin{array}{c}\text { Final } \\
\text { Diagnosi } \\
\text { S }\end{array}$ & \\
\hline & No & $\%$ & No & $\%$ \\
\hline Extratesticular & 89 & 74.1 & 74 & 61.67 \\
\hline Testicular & 31 & 25.8 & 35 & 29.16 \\
\hline Total & $\mathbf{1 2 0}$ & $\mathbf{1 0 0}$ & $\mathbf{1 0 9}$ & $\mathbf{9 0 . 8 3}$ \\
\hline $\begin{array}{c}\text { Table 8: Distribution of cases diagnosed by color } \\
\text { Doppler US and proved pathologically and } \\
\text { surgically scrotal lesions }\end{array}$ \\
\hline
\end{tabular}

